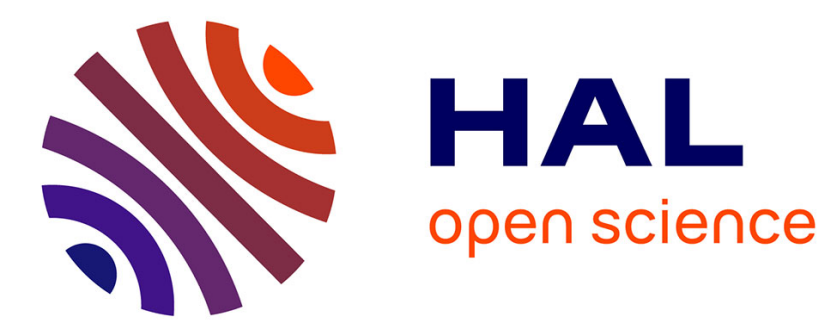

\title{
DISCO synchrotron-radiation circular-dichroism endstation at SOLEIL
}

\author{
Matthieu Réfrégiers, Frank Wien, Ha-Phuong Ta, Lavanya Premvardhan, \\ Stéphane Bac, Frederic Jamme, Valerie Rouam, Bruno Lagarde, François \\ Polack, Jean-Luc Giorgetta, et al.
}

\section{To cite this version:}

Matthieu Réfrégiers, Frank Wien, Ha-Phuong Ta, Lavanya Premvardhan, Stéphane Bac, et al.. DISCO synchrotron-radiation circular-dichroism endstation at SOLEIL. Journal of Synchrotron Radiation, 2012, 59, pp.1109 - 835. 10.1107/S0909049512030002 . hal-01480932

\section{HAL Id: hal-01480932 \\ https://hal.science/hal-01480932}

Submitted on 1 Mar 2017

HAL is a multi-disciplinary open access archive for the deposit and dissemination of scientific research documents, whether they are published or not. The documents may come from teaching and research institutions in France or abroad, or from public or private research centers.
L'archive ouverte pluridisciplinaire HAL, est destinée au dépôt et à la diffusion de documents scientifiques de niveau recherche, publiés ou non, émanant des établissements d'enseignement et de recherche français ou étrangers, des laboratoires publics ou privés. 
Journal of

\section{Synchrotron}

\section{Radiation}

ISSN 0909-0495

Received 20 January 2012

Accepted 1 July 2012

\section{DISCO synchrotron-radiation circular-dichroism endstation at SOLEIL}

\author{
Matthieu Réfrégiers, ${ }^{\mathrm{a} *}$ Frank Wien, ${ }^{\mathrm{a}}$ Ha-Phuong $\mathrm{Ta}_{,}{ }^{\mathrm{a}}$ Lavanya Premvardhan, ${ }^{\mathrm{a}}$ \\ Stéphane Bac, ${ }^{\mathrm{a}}$ Frederic Jamme, ${ }^{\mathrm{a}, \mathrm{b}}$ Valerie Rouam, ${ }^{\mathrm{a}}$ Bruno Lagarde, ${ }^{\mathrm{a}}$ \\ François Polack, ${ }^{a}$ Jean-Luc Giorgetta, ${ }^{a}$ Jean-Paul Ricaud, ${ }^{a}$ Michel Bordessoule ${ }^{a}$ and \\ Alexandre Giuliani ${ }^{a, b}$
}

aSynchrotron SOLEIL, L'Orme des Merisiers, 91192 Gif sur Yvette, France, and b UAR1008, CEPIA,
Institut National de la Recherche Agronomique (INRA), BP 71627, 44316 Nantes, France.
E-mail: refregiers@synchrotron-soleil.fr

The new synchrotron-radiation circular-dichroism (SRCD) endstation on the UV-visible synchrotron beamline DISCO has been commissioned at the SOLEIL synchrotron. The design has been focused on preservation of a high degree of linear polarization at high flux and moderate resolving power covering the vacuum ultraviolet to visible spectral range $(125-600 \mathrm{~nm})$. The beam dimensions have been set to $4 \mathrm{~mm} \times 4 \mathrm{~mm}$ at $1 \mathrm{~nm}$ bandwidth for lower sample degradation. The nitrogen-purged sample chamber fits three types of sample holders accommodating conventional round cell mounting, automated rotation of the samples, as well as a microfluidic set-up. Automated temperaturecontrolled data collection on microvolumes is now available to the biology and chemistry communities. Macromolecules including membrane proteins, soluble proteins, bio-nanotubes, sugars, DNA and RNAs are now routinely investigated.

Keywords: spectroscopy; SRCD; far-UV; linear dichroism; circular dichroism; high throughput.
(C) 2012 International Union of Crystallography Printed in Singapore - all rights reserved proteins with high-resolution techniques such as NMR, X-ray crystallography or electron microscopy (Miron et al., 2005). Indeed, SRCD, like small-angle X-ray scattering and Fourier transform infrared spectroscopy, is becoming a promising contributor in integrated biology (Stanley et al., 2004).

Designs and optical properties of the SRCD experiments vary from synchrotron to synchrotron, therefore users are provided with a diversity of experimental set-ups. It is in the interest of the growing SRCD community that CD spectra are viable and reproducible at the various stations as well as comparable with conventional CD spectra (Wallace et al., 2010). A previous international study concerning conventional CD spectrophotometers has highlighted the 'improved comparability and data quality' obtained in different laboratories (Ravi et al., 2010).

\section{Beamline overview}

An outline of the beamline, including the light extraction at the frontend with its $1.7 \mathrm{~T}$ dipole magnet (bending magnet), the optical design and the concept of the three experimental stations, has been described previously (Giuliani et al., 2009).

Here we focus on the SRCD endstation, with a horizontal and vertical acceptance of $50 \mathrm{mrad} \times 10 \mathrm{mrad}$. The collimated synchrotron radiation beam is focused and propagated (Fig. 1) through four grazing incident mirrors (silicon) into the monochromator (Cinel Scientific Instruments, Italy) and refocused onto the sample with 


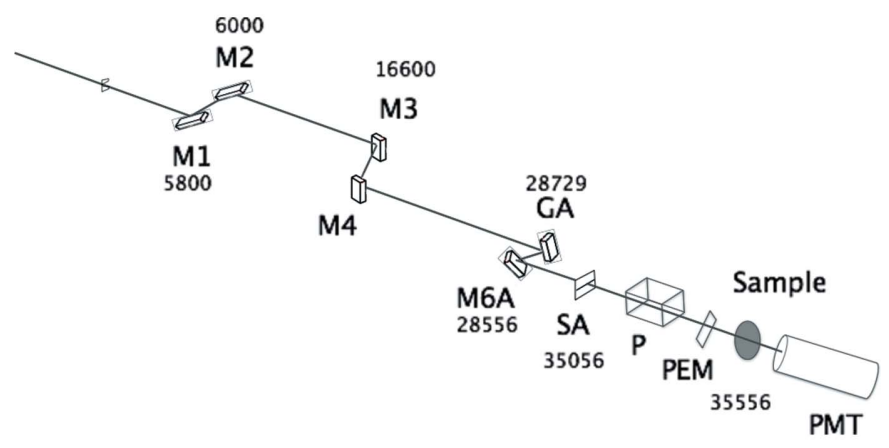

Figure 1

Schematic representation of the part of the beamline of interest for the SRCD endstation. The beam is focused by M2 just before passing through the radioprotection wall. A plane variable-line-spacing grating (GA) monochromatizes the beam before refocusing by a toroidal mirror (M6A). To ensure pure polarization, it passes through a Rochon-type polarizer (P) before being changed to circular light via a photoelastic modulator (PEM), and the detection is provided by locking the high tension (HT) of a photomultiplier tube (PMT). Numbers refer to the distance to the source point in millimetres.

mirror M6A. The beam divergence after the monochromator is $10 \mathrm{mrad}$ (horizontally) and $9 \mathrm{mrad}$ (vertically), reducing the original divergence.

Preservation of the inherent synchrotron beam polarization is an important constraint in the beamline design. The reflectivity of the surfaces as well as the number of reflective planes and their angles have been taken into account, balancing the reflectivities of the s-polarized and the p-polarized radiation through the six optical elements, which include the focusing mirrors and the grating (Table 1).

The ultra-high-vacuum monochromator design includes a normalincident variable-line-spaced grating (400 lines $\mathrm{mm}^{-1}$ ) (HORIBA, Longjumeau, France) of moderate resolving power and a toroidal normal-incident mirror focusing vertically on the exit slits defining the bandwidth and horizontally onto the sample behind the exit window $\left(\mathrm{CaF}_{2}\right)$.

In order to maximize the circular polarized light intensities, the monochromatic beam is linearly polarized using a $\mathrm{MgF}_{2}$ Rochon-type polarizer (Bernhard Halle Nachfolger GmbH, Berlin, Germany) and modulated with a PEM90 photoelastic modulator (HINDS, USA). A diaphragm shields the sample from the scattered radiation minimizing contaminating light of opposite polarization.

Compared with reported monochromator designs (Haass et al., 1994), this design is distinct in two ways: (i) the entrance slit is defined by a diaphragm close to the bending-magnet exit crotch; (ii) the focusing mirror M6A is set right after the grating focusing vertically on the sample. The wavelength range covered by the monochromator extends from $600 \mathrm{~nm}$ down to $125 \mathrm{~nm}$ and is selected through rotation of the incident angle. Possible interference, such as stray light or zeroand higher-orders reflections along the tubing, have been eliminated by the shape of the monochromator housing that includes a light baffle. In the UV range, using inorganic $\mathrm{KCl}$ filters, stray light was found to be less than $2.5 \%$. In addition, in the full accessible range (visible to UV), the recorded vitamin B spectra do not show any interference.

Within the monochromator the variable-line-spaced (VLS) grating and the focusing mirror have been set at normal-incident angles and have been coated with ruthenium. Oxidation of the Al surface would degrade the $\mathrm{s}$ versus $\mathrm{p}$ polarization, while ruthenium does preserve both polarizations. This choice was calculated to optimize for a maximum degree of linear polarization of the synchrotron radiation and to preserve flux $\left(2 \times 10^{10}\right.$ photons $\left.\mathrm{s}^{-1}\right)$ at a moderate resolving
Table 1

Beamline details.

\begin{tabular}{ll}
\hline Beamline name & DISCO SRCD endstation \\
Source type & Bending magnet, 50 $(\mathrm{H}) \mathrm{mrad} \times 10(\mathrm{~V}) \mathrm{mrad}$ \\
Mirrors & Silicon, covered with ruthenium \\
Monochromator & Normal-incidence VLS grating monochromator (Cinel) \\
Wavelength range & $122-600 \mathrm{~nm}$ \\
Beam size on sample & $4 \mathrm{~mm} \times 4 \mathrm{~mm}$ \\
Flux at $400 \mathrm{~mA}$ & $2 \times 10^{10}$ photons s${ }^{-1}$ at $180 \mathrm{~nm}$ \\
Sample mounting & Three possibilities (see text) \\
Detector type & Photomultiplier tube \\
Detector models & Perkin-Elmer C921 $(\varnothing 10.5 \mathrm{~mm}), \mathrm{C} 1321(\varnothing 15.5 \mathrm{~mm})$ or \\
& Electron Tube $9125 \mathrm{~B}(\varnothing 29 \mathrm{~mm})$ \\
Standard acquisition & Scan speed: $35 \mathrm{~nm} \min ^{-1} ; 300 \mathrm{~ms}$ time constant/ \\
parameters & $1.2 \mathrm{~s}$ integration \\
\hline
\end{tabular}

power $(R=\lambda / \Delta \lambda \simeq 300-120)$. The slits opening may be adapted automatically or kept fixed for bandwidth choice.

The focusing mirror (M6A) focuses on the sample $0.5 \mathrm{~m}$ distant from the monochromator slits to a final beam size of $4 \mathrm{~mm} \times 4 \mathrm{~mm}$ (Fig. 1). The beam size was measured using fluorescence from graph paper at $270 \mathrm{~nm}$.

Care has been taken in the design of the exit window. A high-purity $\mathrm{CaF}_{2}$ window (Hellma GmbH, Müllheim, Germany) was thermalbonded into an ultra-high-vacuum flange minimizing distortion due to pressure differences between the vacuum and the nitrogen-purged atmospheric pressurized sample chamber. The cut-off of $122 \mathrm{~nm}$ for $\mathrm{CaF}_{2}$ at $10 \%$ transmission at $300 \mathrm{~K}$ (Hunter \& Malo, 1969) corresponds to the measured nitrogen absorption spectra obtained with an empty chamber (see Fig. 2a); nitrogen peaks are used for absolute calibration of the monochromator (Okabe, 1978); however, for everyday calibration of the spectrometer, a transfer standard, namely the peak positions and ratio of D-10-camphorsulfonic acid (CSA), is used (Fig. $2 b$ ). This allows the complete ratio of polarization to be determined (Kelly et al., 2005). Ultra-high vacuum is required in all optical chambers in order to preserve the surfaces from carbon contamination. The vacuum in the front-end and optical chambers is kept in the low $10^{-9}$ mbar range under beam exposition (Giuliani et al., 2009).

\subsection{Different drawers for different applications}

For faster sample exchange, the sample chamber is only under strong nitrogen purge, nitrogen being sufficiently transparent for VUV spectroscopy down to $120 \mathrm{~nm}$. The sample chamber volume of 2.5 L has been minimized to reduce nitrogen consumption, which runs normally at $10 \mathrm{~L} \mathrm{~min}^{-1}$. The chamber holder was designed for fast sample changing and high versatility. The door is constructed over sliders with magnetic sealing for safe and quick purging after sample changing. Three sample holders were designed for specific applications (Fig. 3b):

(i) The classical sample holder [Fig. 3(b), far right] includes many ports for a range of applications, including laser activation. Using this holder, samples are deposited between two $\mathrm{CaF}_{2}$ windows (Wien et $a l ., 2005)$. With this design it is possible to vary the optical pathway between 6 and $100 \mu \mathrm{m}$.

(ii) The rotating port [Fig. 3(b), far left] allows precise rotation of the sample between each spectrum, with an angular resolution of $0.1^{\circ}$. This holder is dedicated to linear dichroism measurement of films or oriented samples. It is possible to launch a sequence of measurements with a spectrum recorded at each selected angle and to measure anisotropy spectra (Meinert et al., 2012).

(iii) The microfluidic holder [Fig. 3(b), center] includes a microchip in quartz designed to load the sample into position. Moving of the 


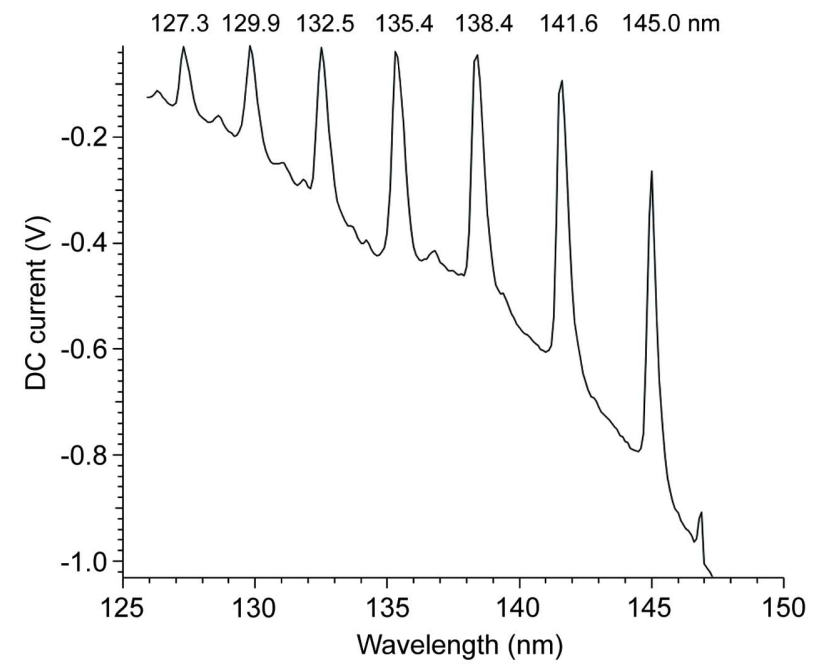

(a)

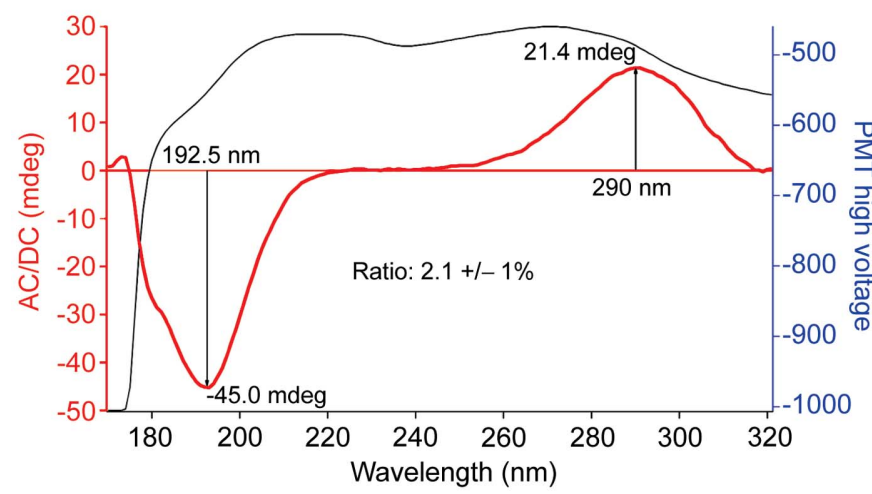

(b)

Figure 2

Calibration of the SRCD spectrometer. (a) Absolute calibration of the monochromator using $\mathrm{N}_{2}$ peaks in the VUV. The chamber was purged with nitrogen, spectral acquisition settings were $0.1 \mathrm{~nm}$ steps, $300 \mathrm{~ms}$ time constant, HT current constant. Peak positions measured in volts of DC current correspond to the literature-referenced absorption peaks. For routine optimization of the optical alignment and electronic recording, peak positions and amplitudes ratio are verified, with a standard CSA solution $6.3 \mathrm{~g} \mathrm{~L}^{-1}$ in $100 \mu \mathrm{m}$ pathlength at $298 \mathrm{~K}(b)$. The thick line shows the CD signal measured in mdeg; the thin line corresponds to the recorded HT measured in volts.

fluids is performed by liquid chromatography micro-pumps. It allows high-throughput experiments with high repeatability, minimizing experimental errors and a high degree of automation for screening; the necessary sample loading volume is around $10 \mu \mathrm{L}$ for a $3 \mu \mathrm{L}$ cell volume capacity. Pathlengths vary from $15 \mu \mathrm{m}$ to $100 \mu \mathrm{m}$ and the flow rate is adjustable between $10 \mu \mathrm{L} \mathrm{min}{ }^{-1}$ and $50 \mu \mathrm{L} \mathrm{min}{ }^{-1}$. Once the sample is in the observation chamber, the valve of the liquid chromatography pump will be automatically switched to pass-by position during a pre-defined time which allows the necessary numbers of data acquisitions. Thereafter the microfluidic cell is flushed out by a cleaning solvent such as water or Hellmanex as required for 5 min at

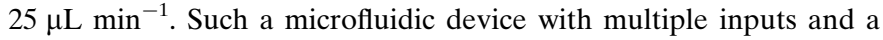
mixing path makes it possible to conduct automatic titration and interaction studies of proteins. A home-made program is developed in parallel in order to automate data processing.

\section{Ancillary facilities overview}

Directly on the beamline, users have access to biochemistry workbenches with a UV spectrometer, dryers, spins and everyday

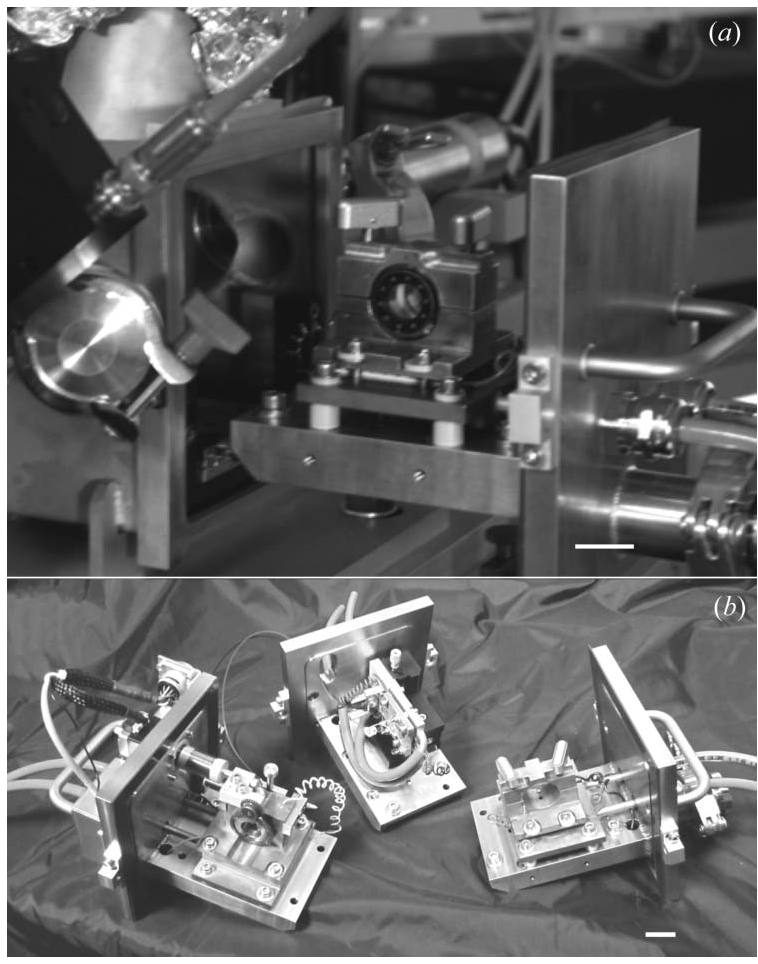

Figure 3

(a) Photograph showing the endstation with the sample chamber and an open drawer. $(b)$ The three thermostated sample-holder drawers can easily be exchanged and repositioned; from left to right, rotating chamber, microfluidic chamber and classic chamber. Scale bars are $22 \mathrm{~mm}$.

consumables. They may also obtain beam time on the two other branches for complementary mass spectrometry (Giuliani et al., 2012) or deep ultraviolet (DUV) fluorescence (Jamme et al., 2010). For deeper biological characterizations, a structural biology laboratory open for users 24/7 is situated only $100 \mathrm{~m}$ away from the endstation; it is fully equipped for protein purification and characterization.

\section{Facility access}

SOLEIL beamlines are under a general user program, accessible through SUNset (http://sunset.synchrotron-soleil.fr/sun). Access to SOLEIL beamlines is open to scientist from around the world. There are two calls for proposals per year with 15 February and 15 September deadlines for submissions.

\section{Highlight}

\subsection{SRCD classics versus high throughput}

An automatic sample handling set-up allowing high-throughput experiments with high reliability and reproducibility is in place. This technique exploits a fully automated synchrotron-radiation circulardichroism spectrometer connected to a microfluidic device and suited to high-throughput screening of different protein conditions. In order to reduce the eventual radiation damage of the samples, the beam is kept broad $(4 \mathrm{~mm} \times 4 \mathrm{~mm})$ at the sample position. No spectral decrease owing to radiation damage could be recorded after 50 consecutive scans. Therefore, care has to be taken for driving the sample to its recording position. Between two measurements, the system is cleaned. Peltier temperature-controlled data acquisition permits automatic denaturation studies between 273 and $383 \mathrm{~K}$ for 


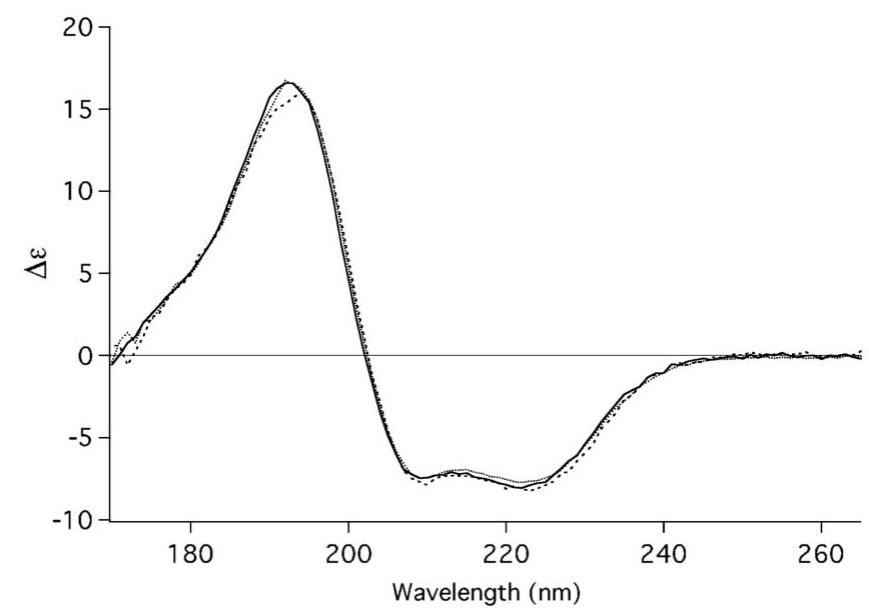

Figure 4

Comparison of myoglobin spectra: charged manually (dotted) in the round cell holders using a $10 \mu \mathrm{m}$ pathlength at $\pm 7 \mathrm{mg} \mathrm{ml}^{-1}$ in $\mathrm{CaF}_{2}$ and in a microfluidic cell at $15 \mu \mathrm{m}$ pathlength (dashes). The presented spectra were averaged over three raw spectra and their respective baselines subtracted, smoothed with step size of 5 (Savitzky Golay) followed by calibration to corresponding concentrations pathlengths and standardized to $\Delta \varepsilon$ units using the mean residue weight of myoglobin $(111.5 \mathrm{Da})$. For comparison a myoglobin spectrum from the reference data set SP175 (continuous line) is shown.

the classical and rotating sample holders in steps of $0.1 \mathrm{~K}$. The range of applications includes denaturation and folding analysis, screening for better crystallization parameters and optimization, as well as ligand binding assessments. The recorded spectra are perfectly matched to 'classical' SRCD spectra (Fig. 4) with no loss of information.

\section{2. $3 \mathrm{~min}$ per spectrum at very high signal to noise}

The influence of the time constant (locking amplifier) and the resulting integration time (four times the time constant) have been assessed, minimizing the noise level (Fig. 5).

\section{Discussion and conclusions}

The SOLEIL synchrotron is a $2.75 \mathrm{GeV}$ third-generation photon source. The flux is well matched to absorption biospectroscopies, therefore the main design efforts were focused on speed of acquisition and conservation of the polarization.

Temperature-controlled circular and linear dichroism as well as absorption spectroscopy in combination with automated sample rotation and continuous microfluidic cell set-ups are now commissioned and routinely used on the DISCO SRCD beamline. The performance of the beamline and especially the high throughput of samples have been the focus of the chamber design along with userfriendly software. Data acquisition, handling and data analysis are at the heart of the software design and adapted to the needs of the users. The whole set-up is controlled through Igor (Wavemetrics) for better data handling and analysis afterwards.

The capabilities of the DUV SRCD endstation of DISCO are presented, opening new ways to analyse biomolecules in solution. The next step will be to increase again the speed of acquisition in order to be able to follow fast kinetics in real time.

We would like to thank the Région Centre for financially supporting the DISCO beamline. HPT is partly funded by Servier. S. V. Hoffmann is gratefully acknowledged for fruitful discussions. This work would not have been possible without the dedication of
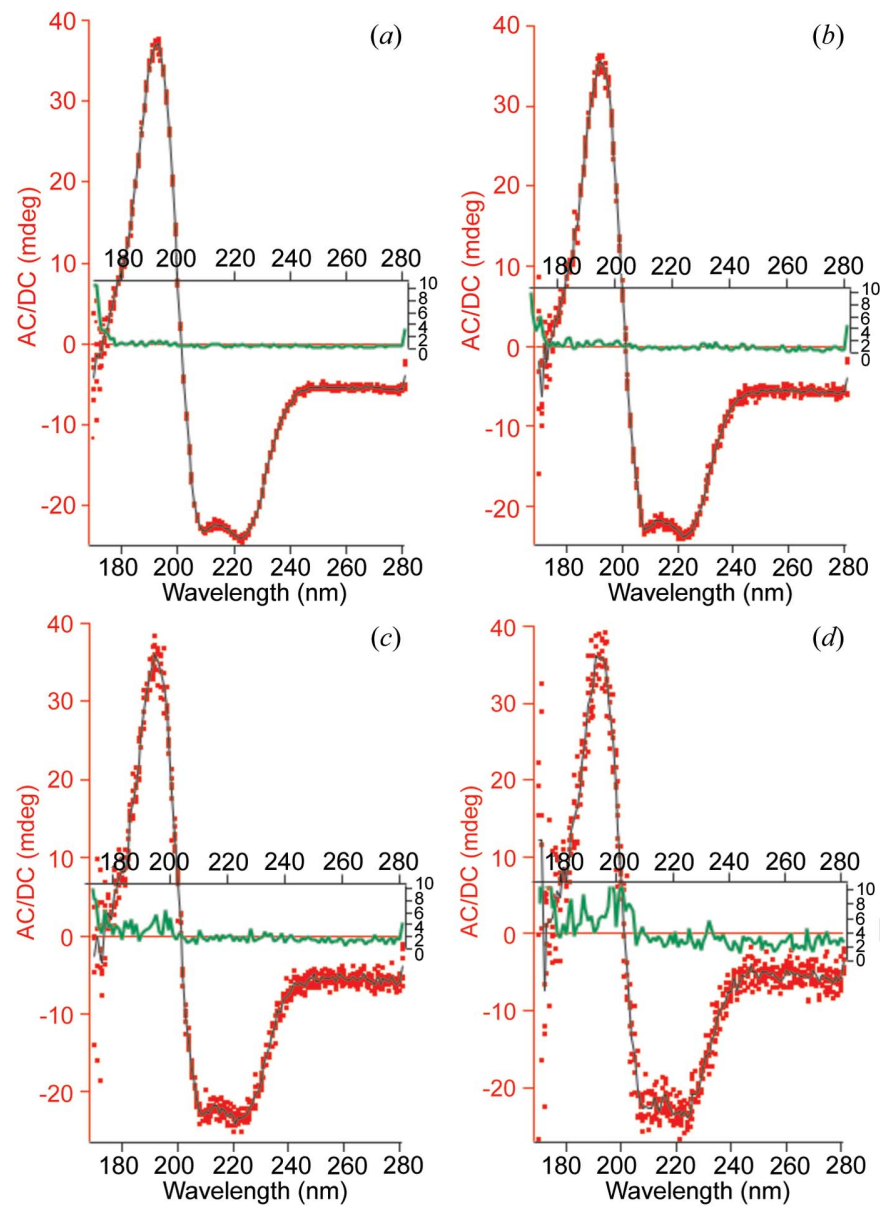

Figure 5

Influence of the speed of acquisition on the signal-to-noise ratio. Four different acquisition time constants (TC set in the lock-in amplifier) resulting in different acquisition speeds demonstrate the signal-to-noise behaviour. (a) $300 \mathrm{~ms}$; (b) $100 \mathrm{~ms}$; (c) $30 \mathrm{~ms}$; (d) $10 \mathrm{~ms}$. The acquisition time per data point corresponds to four times the time constant, also referred to as the integration time. Residuals are overlayed. Three full consecutive scans of myoglobin, $10 \mathrm{mg} \mathrm{ml}^{-1}$ in a $15 \mu \mathrm{m}$ pathlength [raw data, black squares (red online)], have been measured for each dataset, including the return of the monochromator, and the stepping mode of the monochromator of theoretical speed $50 \mathrm{~nm} \mathrm{~min}^{-1}$ (corresponding to $1.2 \mathrm{~s}$ integration time) is reduced to a scan speed of $35 \mathrm{~nm} \mathrm{~min}{ }^{-1}$. Therefore three consecutively acquired spectra with good signal-to-noise ratio are currently produced within $9 \mathrm{~min}$. The residual in percentiles [grey line (green online)] is superimposed on the zero line.

Jean-Claude Maurizot, the chaperon of the DISCO SRCD experiment.

\section{References}

Bousset, L., Bonnefoy, J., Sourigues, Y., Wien, F. \& Melki, R. (2010). PLoS One, $\mathbf{5}$, e9760.

Bulheller, B. M., Miles, A. J., Wallace, B. A. \& Hirst, J. D. (2008). J. Phys. Chem. B, 112, 1866-1874.

Bürck, J., Roth, S., Wadhwani, P., Afonin, S., Kanithasen, N., Strandberg, E. \& Ulrich, A. S. (2008). Biophys. J. 95, 3872-3881.

Clarke, D. T. \& Jones, G. (2004). J. Synchrotron Rad. 11, 142-149.

Cowieson, N. P., Miles, A. J., Robin, G., Forwood, J. K., Kobe, B., Martin, J. L. \& Wallace, B. A. (2008). Proteins Struct. Funct. Bioinform. 70, 1142-1146.

Giuliani, A., Giorgetta, J. L., Ricaud, J. P., Jamme, F., Rouam, V., Wien, F., Laprévote, O. \& Réfrégiers, M. (2012). Nucl. Instrum. Methods Phys. Res. B, 279, 114-117.

Giuliani, A., Jamme, F., Rouam, V., Wien, F., Giorgetta, J.-L., Lagarde, B., Chubar, O., Bac, S., Yao, I., Rey, S., Herbeaux, C., Marlats, J.-L., Zerbib, D., Polack, F. \& Réfrégiers, M. (2009). J. Synchrotron Rad. 16, 835-841. 
Gohon, Y., Vindigni, J. D., Pallier, A., Wien, F., Celia, H., Giuliani, A., Tribet, C., Chardot, T. \& Briozzo, P. (2011). BBA-Biomembranes, 1808, 706716.

Haass, M., Jia, J. J., Callcott, T. A., Ederer, D. L., Miyano, K. E., Watts, R. N., Mueller, D. R., Tarrio, C. \& Morikawa, E. (1994). Nucl. Instrum. Methods Phys. Res. A, 347, 258-263.

Hoffmann, A., Kane, A., Nettels, D., Hertzog, D. E., Baumgärtel, P., Lengefeld, J., Reichardt, G., Horsley, D. A., Seckler, R., Bakajin, O. \& Schuler, B. (2007). Proc. Natl Acad. Sci. USA, 104, 105-110.

Hunter, W. R. \& Malo, S. A. (1969). J. Phys. Chem. Solids, 30, 2739.

Jamme, F., Villette, S., Giuliani, A., Rouam, V., Wien, F., Lagarde, B. \& Réfrégiers, M. (2010). Microsc. Microanal. 16, 507-514.

Jávorfi, T., Hussain, R., Myatt, D. \& Siligardi, G. (2010). Chirality, 22, E149E153.

Kelly, S. M., Jess, T. J. \& Price, N. C. (2005). Biochim. Biophys. Acta, 1751, 119139.

Liu, S.-H., Lin, Y.-H., Huang, L.-J., Luo, S.-W., Tsai, W.-L., Chiang, S.-Y. \& Fung, H.-S. (2010). J. Synchrotron Rad. 17, 761-768.

Matsuo, K., Fukuyama, T., Yonehara, R., Namatame, H., Taniguchi, M. \& Gekko, K. (2005). J. Electron Spectrosc. Relat. Phenom. 144, 1023-1025.
Matsuo, K. \& Gekko, K. (2004). Carbohydr. Res. 339, 591-597.

Meinert, C., Bredehöft, J. H., Filippi, J. J., Baraud, Y., Nahon, L., Wien, F., Jones, N. C., Hoffmann, S. V. \& Meierhenrich, U. J. (2012). Angew. Chem. Int. Ed. 51, 4484-4487.

Miron, S., Réfrégiers, M., Gilles, A.-M. \& Maurizot, J.-C. (2005). Biochem. Biophys. Acta, 1724, 425-431.

Okabe, H. (1978). Photochemistry of Small Molecules. New York: John Wiley and Sons.

Ravi, J., Rakowska, P. D., Garfagnini, T., Baron, B., Charlet, P., Jones, C., Milev, S., Lorenz, J. D., Plusquellic, D., Wien, F., Wu, L., Meuse, C. \& Knight, A. E. (2010). Metrologia, 47, 631-641.

Stanley, W. A., Sokolova, A., Brown, A., Clarke, D. T., Wilmanns, M. \& Svergun, D. I. (2004). J. Synchrotron Rad. 11, 490-496.

Tao, Y., Huang, Y., Qian, H., Yan, Y., Xu, J. \& Zheng, H. (2007). AIP Conf. Proc. 879, 555-558.

Wallace, B. A. (2010). Q. Rev. Biophys. 42, 317-370.

Wallace, B. A., Gekko, K., Hoffmann, S. V., Lin, Y., Sutherland, J. C., Tao, Y., Wien, F. \& Janes, R. W. (2010). Nucl. Instrum. Methods Phys. Res. A, 649, 177-178.

Wien, F. \& Wallace, B. A. (2005). Appl. Spectrosc. 59, 1109-1113. 